\title{
Mulheres no jornalismo contemporâneo: desafios das tecnologias digitais ${ }^{1}$
}

WOMEN IN CONTEMPORARY JOURNALISM: CHALLENGES OF DIGITAL TECHNOLOGIES

\section{Marli Santos}

Doutora em Ciências da Comunicação pela Escola de Comunicações e Artes da Universidade de São Paulo (2004) e mestre em Comunicação Social pela Universidade Metodista de São Paulo (1998). Graduada em Comunicação Social, habilitação em Publicidade e Propaganda (1979) e Jornalismo (1989) pela UMESP. É docente permanente do Mestrado em Comunicação da Faculdade Cásper Líbero, linha de pesquisa Jornalismo, imagem e entretenimento. Vice-coordenadora do GT Estudios sobre periodismo da ALAIC Associación Latinoamerica de Investigadores de Comunicación. É pesquisadora FAPESP - Fundação de Amparo à Pesquisa no Estado de São Paulo. Atuou como coordenadora e docente do Programa de Pós-Graduação em Comunicação Social da UMESP, de 2011 a 2017. Foi docente titular do curso de Jornalismo da UMESP, de 1999 a 2017, tendo orientado inúmeros projetos e trabalhos de conclusão de curso e projetos de iniciação científica. Atuou como docente no Programa de Comunicação Jornalística da PUC-SP e no Sindicato dos Jornalistas Profissionais no Estado de São Paulo. Foi repórter, editora, assessora de imprensa e gerente de comunicação em grandes empresas.

Email: marlijor58@globo.com

\section{Jéssica Oliveira Collado Mateos}

É mestranda de Comunicação Social na Universidade Metodista de São Paulo (UMESP), com bolsa CAPES, sob orientação da Profa. Dra. Marli dos Santos no primeiro ano e do Prof. Dr. Dimas Kunsch a partir de março de 2018. Foi bolsista de iniciação científica PIBIC e da FAPESP - Fundação de Apoio à Pesquisa no Estado de São Paulo e atualmente desenvolve pesquisa no Grupo de Pesquisa Novas Práticas em Jornalismo na UMESP. Graduou-se em Jornalismo na UMESP (2016). É aluna especial do doutorado em Estudos Linguísticos na UNESP, disciplina Tradução, Identidade e Diferença.

Email: mjessicacollado@gmail.com

Recebido em 02/04/2018. Aprovado em 17/10/2018.

1. Artigo apresentado no $14^{\circ}$ Encontro Nacional de Pesquisadores em Jornalismo, realizado em Palhoça, Santa Catarina, em 2016. 


\section{Resumo}

Este artigo apresenta dados preliminares do estudo sobre mulheres no jornalismo contemporâneo, como recorte do projeto de pesquisa "Práticas de investigação jornalística na contemporaneidade e relações de gênero". Tendo em vista a convergência tecnológica e a feminização das redações, o objetivo é verificar a relação da mulher com as tecnologias digitais na produção jornalística em um cenário de abundância de informação. A metodologia utilizada é quantitativa com a aplicação de questionário online (survey). O universo da pesquisa abrangeu 94 jornalistas do Estado de São Paulo, com mais de 21 anos. Os resultados apontam para uma consciência das mulheres em relação às transformações no jornalismo, porém, a maioria está pessimista em relação ao futuro. As jornalistas incorporaram no seu cotidiano a produção multimídia, e a maioria afirma utilizar o JGD no processo jornalístico.

Palavras-chave: Jornalismo contemporâneo. Mulheres jornalistas. Gênero. Tecnologias digitais. Jornalismo Guiado Dados.

\section{Abstract}

This article presents the data of the study about women in contemporary journalism, as a cut from the research project "Practices of journalistic investigation in contemporaneity and gender relations". In view of technological convergence and the feminization of newsrooms, the objective is to verify the relationship between women and digital technologies in journalistic production in a scenario of abundance of information. The methodology used is quantitative with the application of an online questionnaire (survey). The research universe covered 94 journalists from the São Paulo City, with more than 21 years old. The results point to a women's awareness of the transformations in journalism, however, most are pessimistic about the future. The journalists have incorporated multimedia production into their daily lives, and most claim to use Data Driven Journalism (DDJ) in the journalistic process.

Keywords: Contemporary journalism. Women journalists. Guided Journalism.

\section{Introdução}

Este artigo apresenta dados preliminares da pesquisa sobre a atuação das mulheres no jornalismo contemporâneo, tendo em vista dois aspectos essenciais: as práticas jornalísticas na era da informação e a feminização das redações, que abrange quase $64 \%$ dos postos de trabalho. O objetivo é verificar se as repórteres utilizam as tecnologias digitais no trabalho diário, com destaque ao JGD - Jornalismo Guiado por Dados, tendo em vista a tendência de o jornalismo com base em dados ser reconhecida por autores como Barbosa (2013) e Träsel (2014), entre outros.

Embora a tendência é que se fale novamente em crise no jornalismo, não vamos partir desse pressuposto, até porque a crise do jornalismo parece existencial, e eterna, desde o advento do jornalismo moderno, quando a prática se tornou uma atividade lucrativa e se transformou em indústria. Para pensadores como Habermas (2003), se o jornalismo 
foi um dos motores da revolução francesa - disseminando as ideias libertárias com a contribuição dos intelectuais-jornalistas que, ao mesmo tempo, eram engajados na luta -, o jornalismo comercial, comprometido com os interesses das empresas, deixou de contribuir para o debate de temas relevantes na esfera pública.

Agora na era da informação, com o maior acesso às tecnologias e à participação do cidadão, com a Lei de Acesso à Informação (ACESSO À INFORMAÇÃO, 2016)2 com a super segmentação da informação; com a maior velocidade, mobilidade e ubiquidade tecnológica, os mais pessimistas falam no desaparecimento do jornalismo como atividade profissional; os mais otimistas consideram um novo momento, no qual novas formas de produção, distribuição e circulação, além de novas relações com a audiência, são aspectos irreversíveis e positivos, pois caminham em direção a uma prática jornalística mais especia-lizada e democrática, com maior diversidade, e que exige do jornalista novas habilidades.

Essas novas habilidades estão relacionadas à necessidade de organizar e interpretar a profusão de informações disponíveis na internet. De acordo com Barbosa (2013) o paradigma atual é o do JDBD - Jornalismo em Base de Dados, pois o excesso de informação disponível na internet gera novas possibilidades de se organizar, armazenar, investigar e apurar informação na produção jornalística. A ideia de JDBD, ou JGD, nos leva ao conceito de "jornalismo estruturado" que, segundo Lima Júnior e Rosa (2016, p. 4-5), é um

[...] termo que surgiu pela primeira vez numa proposta do editor de inovação e dados da Thomson Reuters, Reginald Chua. Em essência, propõe a fragmentação de narrativas jornalísticas em partes reunidas e relacionadas entre si. Alexis Lloyd, diretora criativa do Laboratório de Pesquisa e Desenvolvimento do The New York Times, revelou que o Project Editor, por exemplo, "analisa a forma como alguns metadados granulares podem ser criados por meio de sistemas colaborativos que dependem fortemente de aprendizado de máquina, bem como inputs editoriais". Chava Gourarie, do Columbia Journalism Review, aponta o artigo Why the Islamic State leaves tech companies torn between free speech and security, do The Washington Post8, como um protótipo de jornalismo estruturado.

2. LAI- Lei de Acesso á Informação. "A Lei no 12.527/2011 regulamenta o direito constitucional de acesso às informações públicas. Essa norma entrou em vigor em 16 de maio de 2012 e criou mecanismos que possibilitam, a qual- quer pessoa, física ou jurídica, sem necessidade de apresentar motivo, o recebimento de informações públicas dos órgãos e entidades. A Lei vale para os três Poderes da União, Estados, Distrito Federal e Municípios, inclusive aos Tribunais de Conta e Ministério Público. Entidades privadas sem fins lucrativos também são obrigadas a dar publicidade a informações referentes ao recebimento e à destinação dos recursos públicos por elas recebidos." Mais informações: http://www. acessoainformacao.gov.br/assuntos/conheca-seu-direito/a-lei-de-acesso-a-informacao. 
O chamado cenário do jornalismo contemporâneo aponta, então, à necessidade de formação de profissionais que compreendam esses aspectos e os incorporem em suas práticas. Nas redações, particularmente no exercício da reportagem, observa-se que a cultura do JDBD, aqui considerado JGD (TRÄSEL, 2014), ainda não está disseminada. Como diz Souza (2016), em seu estudo de doutorado sobre a LAI como canal para fontes informativas, a pesquisadora aponta que durante a crise política no Brasil (2014-2015) o uso de dados disponíveis pela AGU - Advocacia-geral da União em matérias da Folha de S. Paulo e identificados como fontes de informação foram pífios, girando em torno de menos de 5\% dos pedidos encaminhados ao e-SIC - Sistema Eletrônico do Serviço de Informação ao Cidadão.

Tendo em vista que a transição do jornalismo na contemporaneidade, cujas práticas devem ser incorporadas no cotidiano do jornalista em um mercado profissional que se constitui majoritariamente de mulheres, em que medida as novas tecnologias são incorporadas nas rotinas das jornalistas em tempos de jornalismo contemporâneo?

$\mathrm{O}$ foco sobre as mulheres jornalistas se dá pela necessidade de ampliar as pesquisas no âmbito da feminização no jornalismo, já que, além de ser a maioria (em torno de 64\%), o perfil da mulher no mercado de trabalho indica que é quem mais investe na formação educacional, apesar da dupla jornada.

Para tanto, foi realizada uma pesquisa quantitativa, com questionário online (survey), com 29 perguntas estruturadas e abertas, divididas em três eixos: 1) perfil, 2) relação da jornalista com a tecnologia no jornalismo contemporâneo e 3) as relações de gênero na atividade profissional. Porém, neste artigo, será utilizado somente parte dos resultados, especificamente relacionado aos dois primeiros eixos do questionário ${ }^{3}$. O universo da pesquisa são as jornalistas do estado de São Paulo, entre 21 a 50 anos, com experiência em reportagem, independentemente do veículo (rádio, TV, impresso ou internet). O convite para a pesquisa foi encaminhado para grupos de jornalistas, como Farol Jornalismo (site que discute sobre pesquisa e produção de novas formas de jornalismo), e por meio de indicações entre as jornalistas.

Num primeiro momento foram respondidos 50 questionários, porém, selecionados 37, pois 13 não se enquadravam nos filtros propostos na pesquisa. A pesquisa na sua segunda fase de aplicação contará com o apoio do Sindicato dos Jornalistas Profissionais no Estado de São Paulo.

3. O questionário foi dividido em 3 partes: Perfil, Relação com a tecnologia e Relações de gênero. Em razão de sistematização dos dados referentes às Relações de Gênero, os dados não foram incluídos nem analisados neste artigo. 
A seguir apresentamos as características do jornalismo contemporâneo e do JGD, um cenário sobre o perfil da mulher no mercado de trabalho e no jornalismo, além de dados e análises sobre resultados preliminares da nossa pesquisa.

\section{Práticas contemporâneas: o jornalismo na era da informação}

De acordo com Anderson, Bell e Shirky (2013), o jornalismo contemporâneo surge com o avanço da tecnologia, a abundância de informação e dados (estruturados ou não), a decadência da mídia tradicional, a publicidade feita diretamente com o consumidor (B2C), as notícias on demand, além de maior liberdade para se comunicar, por meio das mídias e redes sociais digitais.

A liberdade de comunicação entre o público propicia também a circulação/ recirculação das informações (BARBOSA, 2013), cujos conteúdos podem ser alterados. Some-se ainda a mobilidade propiciada pelos dispositivos digitais móveis, os aplicativos informativos (autóctones ou não) e o feedback em tempo real.

Nesse cenário, o jornalismo perdeu o posto de único arauto da informação, mas ainda mantem a sua função social. Por isso, Anderson, Bell e Shirky (2013) consideram que no jornalismo contemporâneo, ou pós-industrial (como denominam), há um novo papel a ser exercido pelo jornalista e pelas empresas/instituições jornalísticas, inseridos em um ecossistema midiático diferenciado.

Nesse sentido, como destacam os três autores, é necessário estar atento à essência do jornalismo. Mais que isso, é preciso considera-lo uma forma de conhecimento do mundo (GENRO FILHO, 1987). Como dizem Lisboa e Benetti (2015, p. 12- 13), tendo em vista a filosofia do conhecimento, o jornalismo é uma "crença verdadeira justificada". Uma crença porque a credibilidade faz parte da sua essência, a "credibilidade constituída", que é a de quem fala, ou seja, o ethos do jornalismo e do veículo, e a "credibilidade percebida", a do leitor; verdadeira porque busca a verdade, a verdade referencial, como "correspondência aos fatos", dizem as autoras; e justificada porque o método jornalístico é uma maneira de chegar à verdade, ou seja, a verdade é justificada pelo método. Críticas à parte sobre essa definição filosófica do conhecimento, assume-se aqui o jornalismo como forma de conhecimento (GENRO FILHO, 1987), ao lado da ciência e da arte.

Como consideram Anderson, Bell e Shirky (2013), o jornalista terá papel fundamental como especialista, como intérprete da enxurrada de dados, tendo a formação humanística e cultural a seu favor. Para eles, o jornalista passou para um patamar melhor, 
porque vai produzir informação mais especializada. Porém, não descartam que esse profissional terá de se adaptar à nova realidade e lançar mão de novas técnicas de apuração, utilizando dados e metadados - que são informações que classificam dados não estruturados na internet (LIMA FILHO; ROSA, 2016) - a seu favor.

Dessa forma, o jornalismo estruturado em base de dados vai requerer novas habilidades dos profissionais, e muito provavelmente uma nova mentalidade sobre como trabalhar com o JGD, considerando não só conhecimento sobre base de dados e como organizá-las e extrair novas informações e novas pautas, como também ter uma visão mais próxima de compartilhamento, de dados abertos, de colaboração, que é característica da cultura dos hackers. Como diz Träsel, que adota a nomenclatura JGD, Jornalismo Guiado por Dados,

Em especial, o JGD é visto como um tipo totalmente novo de jornalismo, por uma minoria de seus proponentes, e como uma colonização indesejada da informática, por alguns profissionais de outras especialidades. Nos dois casos, é preciso desmistificar a relação entre o JGD e a cultura profissional estabelecida, investigando os valores, práticas e discurso dos profissionais engaja- dos neste tipo de reportagem (TRÄSEL, 2014, p. 301).

Träsel menciona uma possível "imbricação" entre o jornalismo guiado por dados (JGD), com a cultura dos hackers, pois vê nessa convergência de cultura um caminho para a realização de um jornalismo (particularmente no formato reportagem multimídia), que cumpre a "missão de defesa do interesse público [...] assim como uma prática capaz de criar novos caminhos para a narrativa noticiosa e um possível atrativo para uma audiência composta, cada vez mais, por leitores nascidos e criados na cibercultura" (TRÄSEL, 2014, p. 302).

No âmbito das organizações/instituições jornalísticas, Anderson, Bell e Shirky (2013) consideram que as empresas jornalísticas não podem ser reduzidas ao mercado, ao seu aspecto comercial, pois se a atividade editorial não pudesse se preservar da lógica comercial não estaríamos aqui discutindo o futuro do jornalismo, uma vez que seria mais um segmento empresarial com dificuldades. Portanto, há uma visão otimista sobre o futuro do jornalismo, cujo papel e importância como instituição é notável, garantindo seu lugar nos sistemas institucionais (GIDDENS, 1991). As instituições são sistemas necessários, possuem capital simbólico, margem e impacto na sociedade, dizem os três autores, visão que nos faz crer na continuidade das empresas 
jornalísticas consolidadas como também em iniciativas baseadas em organizações cujo modelo não é comercial.

Conforme destaca Costa (2014, p. 64), o modelo industrial anterior, baseado no monopólio da informação, terá de se transformar:

Aquele jeito antigo de produzir informação, cujo monopólio da distribuição pertencia a uma indústria chamada jornalística, mudou. Ela agora pode ser produzida e distribuída pelas mãos de qualquer um. Combinou-se meio e comunicação. Nasceu a superdistribuição. Acabou-se a era industrial do jornalismo, fruto da disrupção no mercado da informação provocada pelo avanço tecnológico que permitiu a sociedade em rede

Porém, ainda é visível a forte influência das grandes empresas no agendamento de temas de relevância nas redes sociais, tema no qual não vamos nos alongar aqui. Mas, como ressaltam Anderson, Bell e Shirky (2013), a democracia não depende mais só do chamado "quarto poder", que denuncia falcatruas do poder público e privado, mas também de outras fontes informativas presentes no ecossistema midiático, em que a participação do cidadão na produção e disseminação de conteúdo, bem como a maior possibilidade de acesso à informação, deflagra um momento de transformação das empresas jornalísticas, pois interferem na audiência, nas formas da publicidade, nas narrativas (que são recirculadas com conteúdo agregado em um fenômeno denominado "remediação"4), na organização da produção e distribuição da informação jornalística.

Dessa forma, é preciso aliar essa nova realidade aos propósitos do jornalismo, que são coletar, narrar e difundir informação socialmente relevante. Para isso, as organizações jornalísticas devem apurar novos métodos, serem transparentes, facilitar o acesso a informações e dados (conteúdo aberto), investir em colaboração e reconhece-las, além de cobrar de organizações públicas, privadas e do terceiro setor, para que informações possam se transformar em dados inteligíveis (metadados) (ANDERSON, BELL, SHIRKY, 2013).

4. A remediação tanto acontece com a remodelagem de mídias quanto com seus conteúdos no ambiente digital, ga- nhando novas narrativas. De acordo com Canavilhas (2010, p. 5), "A migração dos meios tradicionais para a Web esbateu fronteiras e iniciou um processo de convergência que torna cada vez mais difícil distinguir onde acaba um meio e começa outro: a imprensa ganhou distribuição global imediata, uma característica da rádio e da televisão graças aos satélites; a rádio ganhou imagem, característica típica da televisão; a televisão ganhou novos níveis de interacção típicos da Internet. A remediação tornou-se num fenómeno simétrico em que os novos meios melhoram os meios anteriores, mas estes passam igualmente por um processo de transformação que os aproxima dos modelos comunicacionais do novo meio". 


\section{Um breve cenário da mulher no mercado jornalístico}

A feminização das redações tem sido tema de reflexões de alguns pesquisadores, como Santos, Temer e Assis (2013), Temer e Santos (2016), Ribeiro (1998), Ramos (2010), Rocha (2007) e Koshiyama (2001), que abordam o tema no âmbito da formação e das relações de trabalho. Pesquisa sobre o perfil do jornalista brasileiro feita por Mick e Lima (2013) revela o crescimento da presença da mulher nas redações, alcançando quase $63,7 \%$ do mercado de trabalho, com tendência a ampliação desse percentual, uma vez que "na faixa até 30 anos, as mulheres são mais de 69\% da categoria" (p. 33). Nas universidades, embora não se tenha números oficiais sobre a participação da mulher nos cursos de jornalismo no Brasil, é possível supor que a presença também seja maioria. Em estudo do Inep - Instituto Nacional de Estudos e Pesquisas Educacionais Anísio Teixeira, as mulheres são maioria no ingresso ao ensino superior (55\%) e no número de concluintes (60\%). "O percentual médio de ingresso de alunas até 2013 foi de 55\% do total em cursos de graduação presenciais. Se o recorte for feito por concluintes, o índice sobe para $60 \%$ " (PORTAL BRASIL, 2016a).

No que se refere ao panorama da atuação da mulher no mercado de trabalho, verifica-se na pesquisa de Mick e Lima (2013), que a maioria dos cargos de chefia ainda são ocupados por homens, embora esse cenário esteja sendo alterado também. Comparando os dados brasileiros com os dos EUA, verifica-se que tanto na formação quanto na atuação a presença da mulher no jornalismo também é maioria. Temer e Santos (2016, p. 4), citando Heckman, revelam que " $70 \%$ dos estudantes inscritos nos cursos de jornalismo e comunicações são mulheres, em 2002, as mulheres representavam $60 \%$ dos jornalistas abaixo de 25 anos nas redações". No Brasil, dizem as autoras, referindo-se à pesquisa de Mick e Lima (2013), “59\% dos jornalistas são jovens (até 30 anos) ”.

De acordo com a pesquisa do IBGE, divulgada no Portal Brasil (2014b), as mulheres investem mais na formação educacional que os homens.

A pesquisa do IBGE 'Estatísticas de Gênero - Uma análise dos resultados do Censo Demográfico 2010' revelou que a escolaridade das mulheres aumentou em relação à dos homens. O estudo foi baseado no Censo Demográfico, por meio da comparação entre os de 2010 e 2000. A escolaridade é tida como fator que eleva a produtividade de uma economia como um todo, além de gerar outros efeitos virtuosos, como a melhora de salário (PORTAL BRASIL, 2014b). 
A dupla e a tripla jornadas também estão presentes na atuação profissional da mulher, como aspecto que interfere nas relações de trabalho e avanço na carreira, já que as atividades domésticas e os cuidados com a família são relevantes, na presença e continuidade da mulher no mercado de trabalho, o que nos leva a reconhecer que também esses fatores afetam a sua ascensão profissional. O Relatório Anual Socioeconômico da Mulher 2014, citado por Temer e Santos (2016, p. 4) conclui que "os afazeres domésticos e de cuidado dificultam seu acesso e permanência [da mulher] no mercado de trabalho, bem como a sua ascensão profissional”.

Essa situação acarreta em prejuízos à vida profissional, uma vez que as mulheres enfrentam uma sobrecarga, resultante da vida no trabalho e dentro da casa, cristalizando uma "assimetria" que impede mudanças nos "lugares ocupados" na família e fora dela (HIRATA, 2002, p. 193-194). As mulheres "tendem a procurar trabalhos com horários mais flexíveis ou com jornadas parciais para fazer frente às demandas dos cuidados com a família e com o exercício profissional" (RASEAM, 2014, p. 50) (TEMER, SANTOS, 2016, p. 4-5).

A mulher jornalista na contemporaneidade está dividida entre os afazeres da profissão e a vida doméstica, ao tradicional e ao novo, ao público e ao privado. São as características da "terceira mulher”, expressão cunhada por Lipovetsky (2000), usada para definir a mulher contemporânea, que "precisa" corresponder a todas as expectativas nos âmbitos familiar e profissional.

\section{Perfil das mulheres participantes da pesquisa}

Como já foi mencionado anteriormente, nessa fase preliminar de coleta de dados, o perfil das jornalistas que responderam ao questionário online (survey) foi sintetizado por faixa etária, cor, etnia, estado civil, se tem filhos ou não, escolaridade, tempo de profissão e função exercida.

No que se refere a faixa etária, das 94 jornalistas que participaram da pesquisa 27 (29\%) afirmaram estar na faixa etária entre 26 e 30 anos, 20 (21\%) 31 a 35 anos, 17 (18\%) têm mais de 50 anos, 15 (16\%) 36 a 40 anos, 4 (4\%) têm de 21 a 25 anos, 7 (8\%) 41 a 45 anos e apenas 4 (4\%) têm de 46 a 50 anos. A maioria (43\%) tem de 3 a 10 anos de carreira, enquanto 35\% exerce a profissão de 11 a 20 anos, 15\% já está no mercado de 21 a 30 anos e 7\% está há mais de 30 anos no mercado. 
Diante destes números podemos perceber a feminização da profissão nos últimos anos, já que as mais jovens (de 21 a 40 anos) representam 70\% do contingente total. Ana Carolina Temer, Francisco de Assis e Marli Dos Santos (2014, p. 77) explicam que esse fenômeno pode ter ocorrido por causa da entrada gradativa das mulheres no mercado, da profissionalização do jornalismo, da preferência feminina por humanas e por não ser uma profissão consolidada.

Quanto a cor e raça $85 \%$ das mulheres declararam ser brancas, $7 \%$ pardas 5 , $5 \%$ amarelas e $3 \%$ pretas, se participante indígena; $52 \%$ das jornalistas são solteiras, $38 \%$ são casadas, $8 \%$ são divorciadas e $2 \%$ são viúvas e $64 \%$ delas não têm filhos, enquanto 36\% são mães. Segundo Sorj, Fontes e Machado (2007, p. 574-575), mesmo com a inserção das mulheres na esfera pública, elas continuaram sendo responsáveis, em grande medida, pelos cuidados com a família não havendo uma transferência de responsabilidades da esfera privada para os homens. Além disso, os autores (p.590) afirmam que a taxa de participação da mulher no mercado de trabalho depende do tipo de família que estão incluídas, sendo que "as mulheres que mais ingressam no mercado de trabalho moram sozinhas e não formam famílias, [...] enquanto os homens que mais participam do mercado de trabalho são aqueles que formam uma família". Diante desse quadro, pode-se inferir que a alta porcentagem de mulheres solteiras (52\%) e de mulheres sem filhos (64\%) é devido à priorização da carreira.

Já a escolaridade de $47 \%$ das participantes que responderam à pesquisa avança em formação na pós-graduação, particularmente especialização, sendo que $38 \%$ possuem graduação, $10 \%$ mestrado, $3 \%$ doutorado e $2 \%$ somente o segundo grau ou superior incompleto. Na amostra, $79 \%$ das participantes cursaram jornalismo, $17 \%$ possuem uma segunda graduação e $4 \%$ são graduadas em outra área.

Quando questionadas sobre salário mensal, 59\% declararam receber entre $\mathrm{R} \$ 3.152,01$ e $\mathrm{R} \$ 7.880,00,18 \%$ de $\mathrm{R} \$ 7.880,01$ a $\mathrm{R} \$ 15.760,00$, e $\%$ recebem $\mathrm{R} \$ 15.760,01$ ou mais. Apenas 16\% disseram receber de R\$ 1.576,01 a R \$ 3.152,00 mensais. Observou-se que entre as que recebem mais a maioria tem mais idade e maior tempo de experiência.

5. O IBGE considera nas suas pesquisas a classificação de acordo com a percepção do entrevistado. Portanto, embora não haja uma etnia "parda", os brasileiros se declaram como tal. "Os Censos Demográficos 1950 e 1960 reincorporaram o grupo pardo à categorização de cor, como unidade de coleta e análise, sendo os primeiros que orientavam explicitamente, nas instruções de preenchimento, a respeitar a resposta da pessoa recenseada, constituindo a primeira referência explícita ao princípio de autodeclaração" (SABOYA; PETRUCCELLI, 2013, p. 24). 
Foi interessante constatar que a maioria das entrevistadas atua no segmento de internet (mídia eletrônica) ${ }^{6}, 51 \%$ delas afirmaram estar no ramo, seguido de $22 \%$ no setor extra-redação (empresas não jornalísticas) e 18\% em revistas, 17\% em jornal, $7 \%$ em rádio, $5 \%$ em televisão, $3 \%$ em agência de notícia e $17 \%$ em outro setor.

Jenkins, Ford e Green $(2015$, p.57) falam que um passo muito importante ocasionado pelo advento da internet e dos computadores em rede foi dar às mulheres "acesso a novas habilidades e tecnologias quando elas deram seus primeiros passos no ciberespaço, revertendo as concepções iniciais de que somente o sexo masculino teria domínio sobre a cultura digital". Segundo os autores, as mulheres foram as primeiras usuárias de redes sociais, como o LiveJournal, utilizando a tecnologia para criar formas próprias de cultura participativa. Sendo assim, este pode ser o motivo das mulheres estarem em maior número nas mídias digitais, somando-se o fator da crise vivenciada pelos grandes veículos impressos.

Quanto à função ${ }^{7} 52 \%$ das participantes trabalham como repórteres, $34 \%$ editoras/ subeditoras, $23 \%$ redatoras, $21 \%$ assessoras de imprensa, $18 \%$ afirmaram ser jornalistas, $13 \%$ são freelancers, $11 \%$ coordenadoras, $6 \%$ são chefes/gerentes, $4 \%$ ocupam outras funções, $4 \%$ fotógrafas, $3 \%$ são professoras e $1 \%$ empresárias. Vale ressaltar que quase $1 / 5$ das entrevistadas, $18 \%$ somando as que se declararam coordenadoras, chefe ou gerente e empresárias, ocupa cargos mais altos ou tem empresa própria. E entre todas, $76 \%$ já trabalharam como repórter por mais de 3 anos, 18\% exerceram o cargo por menos de 3 anos, enquanto $6 \%$ nunca trabalharam como repórteres.

Portanto, o perfil predominante encontrado é o da jornalista branca, solteira, entre 26 e 30 anos, sem filho, formada em jornalismo e com especialização. Nesse perfil também se observa uma boa experiência na profissão (entre 3 e 10 anos de experiência), com salário que varia entre R \$3.152,01 e R \$ 7.880,00, e atuação como repórter na internet.

\section{Jornalismo e tecnologias}

Os dados apurados indicam que para a maioria expressiva das jornalistas (84\%) o que mudou do jornalismo tido como clássico para o praticado agora foi a introdução de novas tecnologias e processos, seguido de extinção/redução do quadro de funcionários na opinião de $70 \%$. Já 50\% disseram que houve uma precarização da atividade e do ambiente de trabalho, $46 \%$ disseram que houve aumento do ritmo de trabalho e de produtividade exigidos.

6. Pergunta em que a repórter poderia assinalar mais de uma opção em caso de trabalhar em mais de uma mídia.

7. Pergunta em que a repórter poderia assinalar mais de uma opção caso exercesse mais de uma função. 
$\mathrm{Na}$ amostra analisada $38 \%$ das mulheres afirmam que os salários estão cada vez menores, para $29 \%$ as mudanças vieram da reestruturação das empresas. Apenas $10 \% \mathrm{e}$ $9 \%$ afirmaram respectivamente que o que mudou foi a feminização da profissão e a organização do trabalho ${ }^{8}$. Outras $6 \%$ assinalaram a opção outros como alternativa. Todas constatam que a atividade jornalística mudou muito por causa da tecnologia.

A questão seguinte abordou o impacto da tecnologia no trabalho cotidiano da mulher (Gráfico 1).

Gráfico 1 - Tecnologia e trabalho da mulher jornalista

\section{Como você avalia o impacto da tecnologia no seu trabalho diário?}

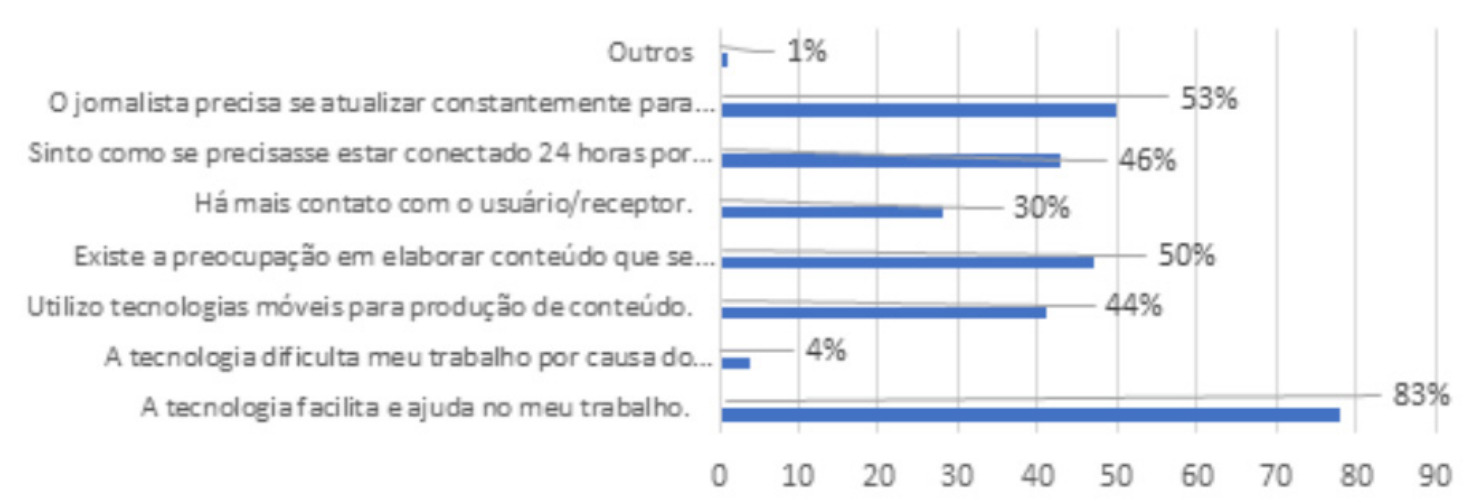

Fonte: Elaborado pelas autoras

Como podemos ver no Gráfico 1, quando questionadas sobre o impacto da tecnologia no trabalho ${ }^{9}$ a grande maioria das jornalistas (83\%) afirma que a tecnologia facilita e ajuda no trabalho delas e que esse jornalismo tecnológico traz consigo preocupação já que 53\% afirmam que o jornalista precisa se atualizar para não ficar defasado. Podemos ver também que para 50\% delas existe a preocupação em elaborar conteúdo que se adeque a mais de uma plataforma, seguido do sentimento de precisarem estar conectadas 24 horas por dia para não perderem informação (46\%) e do uso de tecnologias móveis para produção de conteúdo (44\%).

Em pesquisa feita por Roseli Fígaro sobre o mundo do trabalho dos jornalistas (2012, p. 61), é possível enxergar essas exigências: cobrança para se reinventar e ser multifunção; exclusão dos mais velhos pela falta de intimidade com a internet e pelos salários

8. Pergunta em que a repórter poderia assinalar mais de uma opção.

9. Pergunta em que a repórter poderia assinalar mais de uma opção. 
mais altos, já que a experiência é fator diferencial; falta de tempo para outras atividades (uma jornalista disse ter que parar a pós-graduação porque o horário no emprego mudou e teve que optar pelo trabalho); maior demanda para produzir material para mídias diferentes; terceirização de serviços e relações precárias entre empregadores e contratantes. Outra constatação é a de que o jornalista começa a trabalhar muito cedo, sendo incentivado a ter um emprego antes mesmo de se formar (ibidem, p. 64).

Quando perguntada, novamente, se existe preocupação em elaborar conteúdos que se adequem a mais de uma plataforma o número sobe para $88 \%$ das entrevistadas, o que nos remete ao conceito de multimidialidade no jornalismo digital, uma das características essenciais do jornalismo contemporâneo, de acordo com Palácios (2002, p. 1-2), e também ao fenômeno da convergência midiática e da remediação exposto por Canavilhas (2010, p.5), no qual os meios se convergem e melhoram uns aos outros. "A migração dos meios tradicionais para a Web esbateu fronteiras e iniciou um processo de convergência que torna cada vez mais difícil distinguir onde acaba um meio e começa outro". Em decorrência, o fenômeno da remediação tornou-se "simétrico em que os novos meios melhoram os meios anteriores, mas estes passam igualmente por um processo de transformação que os aproxima dos modelos comunicacionais do novo meio" (CANAVILHAS, 2010, p.5).

Em outra questão nos aprofundamos sobre o tema JGD (TRÄSEL, 2014) ou JDBD (BARBOSA, 2013; LIMA FILHO e ROSA, 2016). A seguir (Gráfico 2), apresentamos os resultados.

Gráfico 2 - Mulheres e Jornalismo Guiado por Dados

\section{Trabalha com base de dados (jornalismo guiado por dados)?}

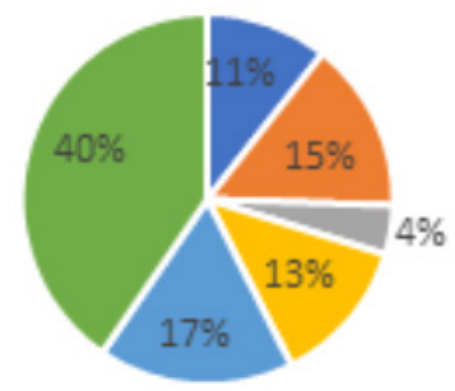

- Nõo sei o que é.

- Não utilizo.

Fonte: Elaborado pelas autoras 
Quando questionadas sobre JGD, somente 13\% afirmaram utilizar com frequência a técnica, 40\% afirmaram utilizar quando necessário, outras 17\% usavam com pouca frequência, $15 \%$ não trabalham com base de dados, $11 \%$ afirmaram não saber o que é JDG e 4\% não utilizam a técnica, mas pretendem. A maioria (70\%) aponta a utilização do jornalismo guiado por dados, porém, Souza (2016) revela em seu estudo sobre a Lei de Acesso à Informação (LAI), que o uso do JGD foi pífio entre os jornalistas que cobriram a crise política no Brasil nos anos de 2014/2015 diante da magnitude do evento. Assim, podemos considerar duas hipóteses: ou as mulheres estão realmente melhor preparadas para a utilização do JGD ou há um equívoco sobre o que efetivamente seja essa prática.

Sobre o futuro do jornalismo, ao contrário de Anderson, Bell e Shirky (2013), as respondentes não estão muito otimistas. Constatamos que $54 \%$ das entrevistadas são pessimistas e que para elas a precarização da profissão tende a aumentar contra os $31 \%$ que são otimistas. Para $2 \%$ a profissão não pode melhorar nem piorar enquanto $13 \%$ assinalaram outros.

A partir dos comentários livres sobre o tema pode-se perceber que as jornalistas colocam ênfase no cenário de transição pelo qual passa o jornalismo e reconhecem ser necessário à jornalista adaptar-se também para conseguir sobreviver no meio. Nas questões abertas, foi possível observar que as profissionais acreditam em iniciativas independentes, longe do mercado, para sua sobrevivência: "Acredito que o futuro está nos jornalistas empreendedores e nos sites independentes". Outras consideram com mais naturalidade esse momento de transição: "Será transformado, haverá sempre uma adaptação", escreve uma das respondentes. Outra jornalista analisa:

Não é uma questão de melhora ou piora e sim de readequação ao novo cenário da comunicação. Os novos conceitos e técnicas devem ser vistos como uma evolução da comunicação. Não dá para frear o progresso porquê de um jeito parece melhor. É apenas diferente e quem aceitar isso terá mais chances de se manter no mercado (Jornalista A, 2016)

Em outros comentários pudemos perceber que algumas jornalistas colocam ênfase no cenário de transição pelo qual passa o jornalismo, destacando certa desvalorização da informação jornalística e os desafios das empresas em adaptarem-se ao novo ecossistema midiático. Uma das respondentes diz:

Vejo que o processo de transição ainda se alongará por alguns anos, e nesse momento específico sobrarão na carreira especialmente os mais jovens e aqueles que não precisam se sustentar, que podem contar com a família financeiramente. Isso até que sejam encon- 
tradas novas formas de se financiar o jornalismo, atividade cara e que hoje se desenvolve em um contexto em que o público já não percebe a informação como algo que tem custo (Jornalista B, 2016).

Em resumo, as participantes disseram que o/a jornalista tem que se enxergar como um produtor de conteúdo, porque os produtos são vários e não há só reportagem; que a crise é do modelo de negócio da mídia e não do bom jornalismo que é sempre necessário à sociedade (o que não se sabe é como o modelo vai se sustentar, porque nenhuma empresa de mídia descobriu exatamente como conciliar conteúdo e dinheiro); é importante que o jornalista pense em inovar e empreender para conseguir ganhar um salário digno; as perspectivas de futuro para os jornalistas são muito desanimadoras, projetam que sobraram na carreira somente os mais jovens e que ganham menos. As jornalistas também chamam a atenção para a importância de as universidades acompanharem essas transformações e ensinarem os alunos sobre os novos formatos e novo contexto do mercado de trabalho jornalístico, porque está acontecendo uma precarização na formação do jornalista. Abaixo, alguns trechos das manifestações espontâneas das entrevistadas na pesquisa.

Vejo duas situações distintas na redação em que trabalho: uma camada de jovens mais abastados que cursam jornalismo e conseguem ingressar na carreira em veículos de prestígio porque o salário baixo não é um problema para eles e, além disso, balanceiam sua falta de experiência com ampla formação geral (viagens, idiomas, cultura). Contraditoriamente, esses jovens não se apegam aos empregos, desistem ou mudam facilmente e são, ao mesmo tempo, os que mais se dedicam a projetos alternativos de jornalismo. E há uma segunda camada, de classe média baixa, de jovens que estudaram jornalismo porque é um curso relativamente barato, geograficamente bem distribuído na cidade - tem a faculdade particular perto de casa ou do trabalho - e pouco exigente, o que permite estudar e trabalhar ao mesmo tempo. Esses jovens acabam mal remunerados nas pequenas assessorias de imprensa e quase nunca conseguem furar a barreira da sua precária educação (além da base acadêmica, falta-lhes, na visão dos contratantes das redações jornalísticas, conhecimento sólido de idiomas estrangeiros, vivência internacional, bagagem cultural geral, ou seja, coisas que o dinheiro proporciona) (Jornalista C, 2016).

Acredito que as novas tecnologias podem abrir o mercado para os jornalistas, porém, cresce a precarização, com baixos salários, aumento da carga de trabalho e falta de especialização, o que acaba, não raro, por comprometer a qualidade do que é veiculado. Outro aspecto a ser considerado é que não raro a atividade jornalística vem sendo exercida por pessoas sem formação adequada que recebem valores abaixo dos pisos da categoria, o que prejudica enormemente a categoria de profissionais (Jornalista D, 2016). 
Por fim, no que se refere às questões de gênero, importante destacar que nos últimos anos as jornalistas começaram a perceber que há diferenças na produção jornalística, em se tratando de pontos de vista, e discriminação profissional também. Embora a maioria reitere que as competências sejam as mesmas (72\%), as jornalistas participantes da pesquisa reconhecem que há um olhar diferenciado nas reportagens feitas pelo gênero feminino (35\%) e diferenças entre os pontos de vista na produção jornalística (38\%), conforme gráfico a seguir.

Gráfico 3 - Jornalistas e relações de gênero

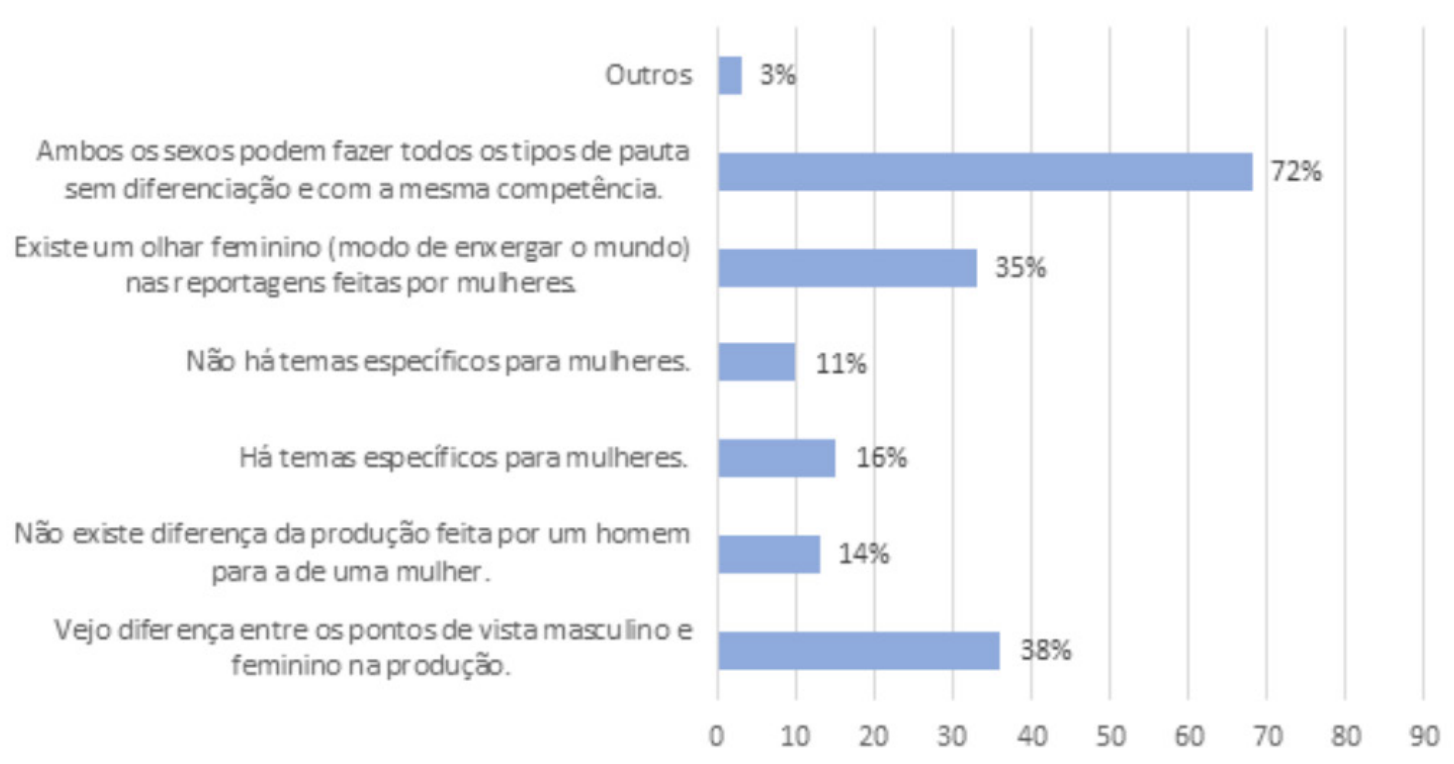

Sobre discriminação no trabalho a percepção é de receberem salários menores que os colegas de profissão (72\%), sendo que $93,6 \%$ das entrevistadas disseram ter sofrido discriminação ou assédio: $43 \%$ por parte da chefia, $37 \%$ por parte das fontes e $22 \%$ por colegas de trabalho. Esses dados nos revelam um jornalismo cuja evolução tecnológica latente e a feminização da profissão não coincidem com a diminuição do preconceito de gênero.

\section{Considerações finais}

Os resultados obtidos nessa fase preliminar nos indicam que é necessário avançar nas pesquisas sobre a mulher no jornalismo contemporâneo, devido à feminização das redações, da maior escolaridade feminina e de algumas características de perfil da mulher trabalhadora, que enfrenta a dupla jornada, recebe menores salários e ocupa menos cargos de chefia. 
Em períodos de transição da sociedade e do mercado de trabalho, particularmente do jornalismo, afetado pela nova realidade da cultura da convergência, especialmente a convergência tecnológica, e do novo ecossistema midiático, questões como precarização do trabalho, exigências na formação e novas habilidades profissionais ligadas ao jornalismo contemporâneo - como a multimidialidade e o uso de dados e metadados para a produção jornalística, em uma cultura de compartilhamento, colaboratividade e dados abertos - acarretam em um sentimento de pessimismo quanto ao futuro do jornalismo. $\mathrm{O}$ JGD no contexto da abundância da informação é uma necessidade nas práticas jornalísticas atuais, de modo a não só diferenciar o profissional, como também qualifica-lo para um mercado de trabalho em transição.

Imersa na realidade do mercado de trabalho, é a dimensão essencial do jornalismo que o legitima enquanto prática social, enquanto discurso asseverativo da realidade (CHAPARRO, 1999), enquanto forma de conhecimento do mundo (GENRO FILHO, 1987). Como já dissemos, citando Lisboa e Benetti (2015), no ethos jornalístico está intrínseco o valor da credibilidade, a qual está atrelada a verdade como correspondência aos fatos e o método jornalístico como o caminho que possibilita chegar à verdade. Portanto, é preciso atualizar o método, diversificá-lo, ampliá-lo, sem preconceitos, e usá-lo a favor do jornalismo como atividade social relevante, que resguarda a democracia e o interesse público.

Finalmente, na relação das mulheres com o jornalismo contemporâneo é possível vislumbrar um futuro com mais otimismo (mesmo que elas eventualmente estejam pessimistas), pois a evolução de sua atuação no mercado profissional, apesar das demandas do ambiente doméstico e profissional, aponta para profissionais interessadas em melhor se preparar para os desafios do jornalismo no século 21 .

\section{Referências}

ACESSO À INFORMAÇÃO. LAI - Lei de acesso à informação. Disponível em: http://www. acessoainformacao.gov.br/assuntos/conheca-seu-direito/a-lei-de-acesso-a-informacao. Acesso em: 21 de julho 2016.

ANDERSON, C.W.; BELL, Emily; SHIRKY, Clay. Jornalismo Contemporâneo: adaptação aos novos tempos. Revista de Jornalismo ESPM, São Paulo. Editora ESPM, abril-junho de 2013, p.30-89. 
BARBOSA, Suzana. Jornalismo convergente e continuum multimídia na quinta geração do jornalismo nas redes digitais. In: CANAVILHAS, João. Notícias e mobilidade: o jornalismo, na era dos dispositivos móveis. Disponível em http://www.labcom- ifp.ubi.pt/ficheiros/20130404-201301_ joaocanavilha_noticiasmobilidade.pdf. Acesso em 20 de julho 2016.

CANAVILHAS, João. O novo ecossistema midiático. Disponível em http://www.bocc.uff.br/ pag/canavilhas-joao-o-novo-ecossistema-mediatico.pdf. Acesso em 20 de mai 2016.

CHAPARRO, Manuel Carlos. Pragmática do jornalismo: buscas práticas para uma teoria da ação jornalística. São Paulo: Summus, 1994.

FÍGARO, R. O perfil do jornalista e os discursos sobre o jornalismo. Um estudo das mudanças no mundo do trabalho do jornalista profissional em São Paulo. Grupo de Pesquisa Comunicação e Trabalho, São Paulo, ECA/USP, 2012.

GENRO FILHO, Adelmo. O segredo da pirâmide: para uma teoria marxista do jornalismo. Porto Alegre: Tchê, 1987.

GIDDENS, Anthony. As conseqüências da modernidade. São Paulo : UNESP, 1991.

HABERMAS, Jürgen. Mudança estrutural da esfera pública: investigações quanto a uma categoria da sociedade burgues. Tradução: Flávio R. Kothe. Rio de Janeiro: Tempo Brasileiro, 2003.

KOSHIYAMA, Alice Mitika. Mulheres jornalistas na imprensa brasileira. In: Anais do XXIV Congresso Brasileiro de Ciências da Comunicação, Campo Grande (MS, Brasil), entre 3 e 7 de setembro: 1-11, 2001.

JENKINS, H.; FORD, S.; GREEN, J. Cultura da conexão: criando valor e significado por meio da mídia propagável. São Paulo: Aleph, 2015.

LIMA JUNIOR, Walter Teixeira; ROSA, André. Jornalismo estruturado: uso de metadados para enriquecimento de bases noticiosas na web. Anais do XXV Encontro Nacional da Compós, Universidade Federal de Goiás, 7-9 de junho de 2016. Disponível em: http://www.compos.org.br/ biblioteca/160224_compos_artigo_nomes_3370.pdf. Acesso em 20 de jul 2016.

LIPOVETSKY, Gilles. A Terceira Mulher. Instituto Piaget, Lisboa, 2000 
LISBOA, Sílvia; BENETTI, Marica. O jornalismo como crença verdadeira justificada. Brazilian Journalism Research, Vol. 11, nº 2, 2015, pp 10-29

MICK, Jacques; LIMA, Samuel. Perfil do jornalista brasileiro: características demográficas, políticas e do trabalho jornalístico em 2012, Florianópolis: Insular, 2013.

PALÁCIOS, Marcos. Jornalismo online, informação e memória: apontamentos para o deba- te. Disponível em http://labcom-ifp.ubi.pt/files/agoranet/02/palacios-marcos-informacao- memoria. pdf. Acesso em junho 2016.

PALÁCIOS, M. Jornalismo online, informação e memória: apontamentos para o debate. In: painel Informação e Jornalismo, evento Jornadas sobre jornalismo online, Universidade da Beira Interior, 2002. Disponível em: http://labcom-ifp.ubi.pt/files/agoranet/02/palacios-marcos-informacao-memoria.pdf. Acesso em 11 jun. 2016.

PETRUCCELLI, José Luiz; SABOIA, Ana Lucia (Orgs). Características étnico-raciais da população: características e identidades. IBGE. Disponível em http://biblioteca.ibge.gov.br/visualizacao/livros/liv63405.pdf. Acesso em 15 de maio 2016.

PORTAL BRASIL. Mulheres são maioria no ingresso e na conclusão de cursos superiores. 2015. Disponível em: http://www.brasil.gov.br/educacao/2015/03/mulheres-sao-maioria-no-ingresso-e- na-conclusao-de-cursos-superiores. Acesso em: 20 de jul 2016.

PORTAL BRASIL. Escolaridade das mulheres aumenta em relação à dos homens. 2014a. Disponível em: http:/www.brasil.gov.br/cidadania-e-justica/2014/11/escolaridade-das-mulheresaumenta-em-relacao-a-dos-homens. Acesso em: 28 de jul 2016.

PORTAL BRASIL. Mais brasileiras esperam chegar aos 30 para ter primeiro filho. 2014b. Dispo- nível em: http://www.brasil.gov.br/saude/2014/10/mais-brasileiras-esperam-chegar-aos-30-para- ter-primeiro-filho. Acesso em: 28 de jul de 2016.

RAMOS, Regina Helena de Paiva. Mulheres jornalistas: a grande invasão. São Paulo: Imprensa Oficial do Estado de São Paulo, Faculdade Cásper Líbero, 2010.

RIBEIRO, José Hamilton. Jornalistas, 1937 a 1997: história da imprensa de São Paulo vista pelos que batalham laudas (terminais), câmeras e microfones, São Paulo: Imprensa Oficial do Estado de São Paulo, 1998 
SOUZA, Rose V. LAI - Lei de Acesso à Informação: um canal à fonte de informação noticiosa. Tese. São Bernardo do Campo, Universidade Metodista de São Paulo, 2016.

TEMER, Ana Carolina R. P; ASSIS, Francisco; SANTOS, Marli. Mulheres jornalistas e a prática do jornalismo de imersão: por um olhar sem preconceito. Disponível em http://www.cimj. org/revista/25/AnaTFranciscoAMarliS.pdf. Acesso em 20 jun. 2016.

TEMER, Ana Carolina R. P; SANTOS, Marli. Subjetividades femininas na cobertura jornalística. In: ENCONTRO NACIONAL DA COMPÓS, 25., 2016. Anais [...]. Universidade Federal de Goiás, 7-9 de junho de 2016. Disponível em: http://www.compos.org.br/biblioteca/subjetividadesfemininasnacoberturajornal\%C3\% ADstica- autoria_3368.pdf. Acesso em: 20 jun. 2016. 